\title{
ANÁLISIS SEMIÓTICO DEL LOGO DE MOZILLA
}

\section{SEMIOTIC ANALYSIS OF MOZILLA LOGO}

\author{
AUTORA \\ María del Carmen Llorente Barroso \\ Investigadora OTRI-UCM en Optimedia. Madrid. (España) \\ carmenllore@gmail.com
}

\section{RESUMEN}

Los logo-símbolos (popularmente conocidos como logotipos o logos) configuran un código autónomo que permite hablar de una Semiótica Visual Corporativa general, a la que se ciñen las Semióticas Visuales Corporativas locales que desarrolla cada una de las empresas y cuyas significaciones se construyen en forma de símbolos. Precisamente esa considerable carga simbólica determina el fuerte carácter local de ese código y manifiesta la complejidad semiótica del código por la dificultad que existe de establecer un grado cero.

Cada uno de estos códigos locales se configura, por tanto, como una semiótica débilmente codificada, inestable y polisémica. De esta manera, la consecución de un sentido adherido al signo visual que representa la marca se logra con el tiempo y después de un esfuerzo comunicativo por parte de esa marca. No obstante, pese a la localidad manifiesta de tales códigos visuales existe una serie de índices generales, 


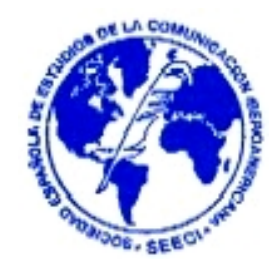

que posibilita la existencia de esa Semiótica Visual Corporativa que permite identificar un logo-símbolo como tal y no como otro tipo de signo visual.

\section{PALABRAS CLAVE}

Semiótica - Identidad Visual Corporativa - Logo-símbolo- Logotipo - Logo - Semiótica Visual.

\section{ABSTRACT}

Logo-symbols (popularly known as logotypes or logos) form an autonomous code that lets talk about a general Visual Corporate Semiotics which specific Visual Corporate Semiotics are restricted to the former. Those Semiotics are developed by each of the companies and their meanings are constructed as symbols. Precisely, that considerable symbolic load determines the strong local character of the code and manifests the semiotic complexity of the code because of the difficulty of establishing a zero degree.

Each of these specific codes is set, therefore, as a semiotic weakly encoded, unstable and polysemous. Thus, the sense that is joined to the visual sign that represents the brand is only achieved with time and after a communicative effort developed by that brand. However, despite the location of such visual codes, there are a number of general indices which allow the existence of the Visual Semiotics to identify a corporate symbol as such and not as another kind of visual sign.

\section{KEY WORDS}

Semiotics - Visual Identity Corporate - Logo-symbol- Logotype - Logo - Visual Semiotictics. 


\section{ÍNDICE}

1. Introducción

2. Objetivos

3. Metodología

4. La semiótica visual corporativa.

Una aproximación al concepto de Semiótica.

La complejidad de una Semiótica Visual General.

El logo-símbolo, signo visual.

4.2.1. Los elementos semióticos que componen el logo-símbolo.

5. Análisis semiótico del logo de Mozilla.

5.1. Modelo de análisis de las unidades de registro semiótico.

5.2. Registro semiótico e interpretación de los datos.

5.2.2. El análisis del logo-símbolo de Mozilla Firefox como signo visual de estructura tripartita y relacional.

6. Conclusiones.

7. Bibliografía. 


\section{Introducción}

Los signos visuales corporativos, concretamente los logo-símbolos ${ }^{1}$, popularmente conocidos como logotipos, constituyen un código visual autónomo de marcado simbolismo. No obstante, a pesar de la importante carga retórica del lenguaje de los logos, debe considerarse previamente, la existencia de un código primario esencialmente referencial que permita diferenciar todas aquellas desviaciones que constituirían un sistema retórico alternativo.

Ese código podría determinarse como una Semiótica Visual Corporativa, más estable pero sólo alcanzable con el tiempo y una Comunicación Corporativa paralela desarrollada por las marcas para la consecución de un lenguaje especialmente local que, sin embargo, responde a los principios generales de esa Semiótica Visual Corporativa y permite la identificación de un logo como tal y no como otro tipo de imagen.

En este modesto trabajo se expone el análisis semiótico del logo de Mozilla Firefox como caso que demuestra la existencia de mencionado código.

\footnotetext{
${ }^{1}$ Justo Villafañe (1999: 69) considera que un logo-símbolo es una combinación normalizada entre símbolo y logotipo. En este caso se considera que esta representación puede manifestar tres formas expresivas:

- El logotipo: Es el diseño tipográfico, que constituye el nombre propiamente dicho de la empresa y, en ocasiones, la propia marca (Villafañe, Justo, 1999: 69). A veces, una marca reduce la expresión de su Identidad Corporativa a un logo-símbolo exclusivamente tipográfico.

- $\quad$ El símbolo: Es un signo visual que simboliza la Identidad Corporativa. Norberto Chaves (1988: 51) denomina a este signo visual imagotipo.

- El logo-símbolo, en sentido estricto, es una combinación simbiótica y normativa del logotipo y el símbolo para expresar, de forma completa y general, la Identidad Visual Corporativa de una empresa (Villafañe, Justo, 1999: 69). Se trata de la forma expresiva más completa, que permite el lenguaje logo-simbólico, al contener una parte exclusivamente visual (el símbolo) y otra parte exclusivamente tipográfica (el logotipo).
} 


\section{Objetivos}

Los objetivos que se proponen en el desarrollo de este trabajo analítico y que lo orientan son:

1. Determinar la existencia de un código semiótico logo-simbólico.

2. Analizar la debilidad/fortaleza de mencionado código autónomo.

3. Identificar los elementos constitutivos del signo en el logo-símbolo.

4. Identificar las relaciones entre los elementos semióticos que componen el logo-símbolo.

5. Determinar la existencia de una Semiótica Visual Corporativa general, así como de una serie de Semióticas Visuales corporativas de carácter local que se ciñan a las normas de la general.

\section{Metodología}

La consecución de tales objetivos determina un desarrollo metodológico basado en un único método, un análisis discursivo de un caso ejemplar. Así se lleva a cabo el estudio semiótico del logo de Mozilla Firefox, desde una perspectiva analítica ya utilizada por el Grupo Mi (1993) y fundamentada en el modelo triangular del signo propuesto por Charles Kay Ogden y Ivor Armstrong Richards (1923).

Así se estudia el caso propuesto como un signo de estructura tripartita y relacional, lo que ofrece una serie de resultados acordes a los objetivos planteados y extrapolables a una dimensión más amplia. De esta manera se consigue extraer ciertas inferencias de interés que demuestran, dentro de la modestia de este trabajo, 
la existencia, de una Semiótica Visual Corporativa a la que se ciñen los códigos visuales corporativos locales desarrollados por las marcas.

\section{La semiótica visual corporativa.}

En una aproximación a la conceptualización de la Semiótica Visual, dentro de la que se enmarcaría una más específica que regula el lenguaje de los signos visuales corporativos, se desarrolla la compilación Figuras y Estrategias: En torno a una Semiótica de lo Visual, desarrollada por Gabriel Hernández Aguilar (1994), y en la que se aglutinan obras de prestigiosos autores sobre breves y específicos estudios que pueden enmarcarse en lo que podría considerarse una Semiótica Visual General. De tales autores, destaca Algirdas J. Greimas (1994: 17-42), cuya aportación insiste en la existencia de una Semiótica Figurativa y una Semiótica Plástica, reconociendo, que a pesar de los esfuerzos realizados, la Semiótica Visual no ha logrado dominar el amplio campo de significaciones que pretende reagrupar, bajo ese modo de expresión (visual), en parte porque, a su entender, aún no está elaborada la Teoría de lo Visual.

\subsection{Una aproximación al concepto de Semiótica.}

Para poder determinar una definición de Semiótica Visual Corporativa, es necesario, previamente, determinar la conceptualización de Semiótica. A lo largo de la historia se han desarrollado dos concepciones muy próximas relativas al estudio de los signos, cada de las cuales ha girado en torno a los dos autores que idearon respectivos términos, entre los que no existen importantes diferencias: 


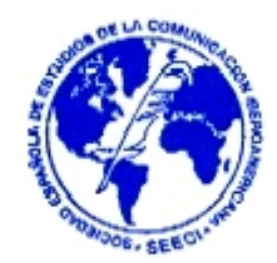

- La Semiología se ha vinculado más a la tradición europea encabezada por Ferdinand de Saussure; esta perspectiva considera la Semiología como una ciencia esencialmente social y humana, determinando que el signo es una entidad de estructura binaria y sistémica. Ferdinand de Saussure, centrado en el estudio de la Lingüística, definió la lengua como "un sistema de signos que expresan ideas" (Saussure, Ferdinand, 1945: 60), concibiendo "una ciencia que estudie la vida de los signos en el seno de la vida social' (Saussure, Ferdinand, 1945: 60), de la que la Lingüística, sería una parte más. Tal ciencia, formaría parte de la Psicología Social y él se refirió a ella como Semiología, definiendo su función del siguiente modo: "Ella nos enseñará en qué consisten los signos y cuáles son la leyes que los gobiernan" (Saussure, Ferdinand, 1945: 60).

- La Semiótica se ha vinculado a la tradición anglosajona encabezada por Charles Sanders Peirce; esta perspectiva destaca el carácter lógico y formal de la disciplina, considerando que el signo es una entidad triádica y pragmática. Charles Sanders Peirce considera que "la lógica, en su sentido general, es, como creo haberlo demostrado, sólo otro nombre de la Semiótica, la doctrina cuasi-necesaria, o formal, de los signos" (Peirce, Charles Sanders, 1974: 21).

Hoy se ha extendido el uso general del término Semiótica para hacer referencia a la ciencia que se encarga del análisis de los signos, se consideren éstos en su estructura bidimensional o triádica. Al respecto y de forma general, resultan muy interesantes los apuntes de Umberto Eco (2000), quien, desde la definición misma de esta ciencia, considera la posibilidad de que el signo represente a una cosa inexistente:

"La Semiótica se ocupa de cualquier cosa que pueda considerarse como signo. Signo es cualquier cosa que pueda considerarse como substituto significante de cualquier otra cosa. Esa cualquier otra cosa no debe necesariamente existir ni debe subsistir de hecho, en el momento en que el signo la represente. En ese 
sentido, la Semiótica es, en principio, la disciplina que estudia todo lo que puede usarse para mentir" (Eco, Umberto, 2000: 22).

Algirdas J. Greimas y Joseph Courtés (1982) contemplan en su Semiótica: Diccionario razonado de la Teoría del Lenguaje, las diferentes acepciones que puede manifestar la Semiótica:

"El término Semiótica se emplea con diferentes sentidos, según que designe (A), una magnitud cualquiera manifestada, a la que se propone conocer; $(B)$ un objeto de conocimiento, tal como aparece durante y después de su descripción, y (C) el conjunto de medios que hacen posible su reconocimiento" (Greimas, Algirdas J. y Courtés, Joseph, 1982: 364).

Por tanto, puede considerarse de forma general que la Semiótica es la ciencia de los signos; sin embargo, hablar de ella, significa hablar del lenguaje y de los rasgos que definen a este tipo de sistemas de signos que conforman códigos; un modelo ideal de código semiótico, independientemente de su naturaleza, es aquel que presenta, según Louis Hjelmslev (1987), los siguientes rasgos:

- Una correspondencia biunívoca e intencionada entre el plano de la expresión y el del contenido: "Por razones puramente lógicas parece obvio que cualquier lenguaje concebible entraña dos cosas: Una expresión, y algo expresado" (Hjelmslev, Louis, 1987: 177). Para Louis Hjelmslev (1987), no puede existir una expresión sin algo expresado, lo que convierte a cualquier lenguaje en un código semiótico de estructura doble o de dos lados (planos), el de la expresión y el del contenido. 
- Un segundo rasgo común a todos los lenguajes es la correlación entre dos ejes, la sucesión y el sistema. En toda estructura lingüística, según Louis Hjelmslev (1987), hay un eje de sucesión, de tal manera que aunque el lenguaje es un sistema, lo que observamos, de forma inmediata, no es un sistema, sino una sucesión, lo que correspondería, en la Lengua, a un texto, tras el cual se podrá detectar ese sistema, esto es, la lengua en sí misma (Hjelmslev, Louis, 1987: 182).

- El tercer rasgo fundamental en la estructura básica del lenguaje es la conmutación, que consiste en una relación entre relaciones de contenido y relaciones de expresión.

- El cuarto rasgo fundamental de la estructura básica del lenguaje es la existencia de relaciones definidas entre unidades (Hjelmslev, Louis, 1987: 210).

Sin embargo, estos rasgos sólo los manifiestan las Semióticas fuertemente codificadas (Grupo Mi, 1993: 234), caracterizadas no sólo por una neta segmentación entre los planos de la expresión y del contenido (perfectamente formalizados), sino también porque las relaciones entre las unidades de cada uno de estos planos están fuertemente tipificadas y estabilizadas. Un conjunto de Semióticas al que no pertenece la Semiótica Visual Corporativa, dado que la formalización de sus planos es débil y fluida, mientras que las relaciones entre sus unidades se presentan inestables y complicadas, variando en cada caso concreto.

El concepto de Semiótica conforma una de las bases conceptuales de la Semiótica Visual Corporativa, en el que además, se diferencian otros dos términos, cada uno de los cuales contribuye a su significación definitiva: 
- Semiótica, porque es un sistema de signos que se relacionan entre sí y, en cuyo seno, se establecen relaciones que los conocedores del código son capaces de comprender, interpretar y utilizar. En este sentido, se trata de un lenguaje, como muy bien apunta Javier González Solas (2002: 139): "Los signos forman lenguajes que sirven para comunicar".

- Visual, por la naturaleza de esos signos, esto es, por la sustancia semiótica; la sustancia semiótica, para Louis Hjelmslev, es sinónimo del sentido tomado por una forma, con vistas a la significación (Greimas, Algirdas J. y Courtés, Joseph, 1982: 398); respecto a la forma semiótica, que es una invariante, la sustancia semiótica debe ser considerada como una variable, ya que una forma semiótica puede manifestarse a través de muchas sustancias (fónica, gráfica, visual, etc.). La sustancia esencial del logo-símbolo es la visual, pues son imágenes con determinadas características, pero imágenes al fin y al cabo, que percibimos a través de la vista.

- Corporativa, por su contenido, porque los logo-símbolos expresan los valores identitarios de una empresa, corporación o entidad.

Como conclusión a tales consideraciones podemos tomar prestada la sentencia realizada por Javier González Solas (2002: 139):

"El lenguaje de la imagen llamada corporativa puede considerarse un lenguaje particular, quizás una Semiótica específica, una metasemiótica, construida a partir de materiales previos ya establecidos tales como el lenguaje natural, el escrito, la imagen, el color. Sin ser pretenciosos, al menos se podría decir que constituye un dialecto, o un idiolecto, del amplio lenguaje de la imagen funcional, 
compuesta asimismo por imagen, en sentido convencional, y texto (González Solas, Javier, 2002: 139).

\subsubsection{La complejidad de una Semiótica Visual General.}

Para poder profundizar en el ámbito de esta Semiótica o Semiología Visual Corporativa, resulta fundamental hacer referencia a las importantes aportaciones del Grupo Mi (1993). Los investigadores de este grupo diferencian, dentro de los signos visuales, los icónicos y los plásticos, refiriéndose a los icónicos como imágenes figurativas y a los plásticos como imágenes no figurativas. En esta investigación, sine embargo, no se considera tal diferenciación, al considerar que todo signo visual manifiesta un determinado grado de abstracción variable, no sólo en función de su grado de iconocidad respecto al referente al que representa, sino también en función de su capacidad connotativa. Efectivamente, una imagen puede mantener muchos rasgos de parecido con su referente real, pero puede encerrar significados connotativos que le confieran un alto grado de abstracción y ésta es una de las características fundamentales de todo símbolo, también de los corporativos.

Pero el Grupo Mi (1993) sienta algunas de las bases en este campo de investigación. En este sentido, considera la existencia de dos tipos de Semióticas (Grupo Mi,1993: 236)

- Un tipo de Semióticas fuertemente codificadas, caracterizadas por:

o La segmentación neta entre el plano de la expresión y el plano del contenido.

o La estable relación entre las unidades de cada uno de esos planos. 
- Un tipo de Semióticas débilmente codificadas, caracterizadas por:

o La segmentación vaga entre el plano de la expresión y el plano del contenido.

o La inestable relación entre las unidades de cada uno de esos planos.

Mencionado grupo de investigadores considera que los logotipos más famosos, como las flechas indicadoras, los estereotipos icónicos o el bastón blanco de un ciego, pertenecen a Semióticas fuertemente codificadas (Grupo ，1993: 236), pero entonces, ¿qué pasa con los logo-símbolos poco famosos? Si una empresa ha logrado que su firma visual sea reconocida mundialmente y asociada a una serie de valores positivos es debido al empeño que han puesto en repetirnos lo que significa. En ese sentido, existen marcas que han creado todo un lenguaje de símbolos visuales a los que asociamos significados arbitrarios que hemos aprendido de forma similar a como aprendemos los contenidos que corresponden a cada grafía lingüística. Podemos hablar por ello de una Semiótica Visual Corporativa de CocaCola, que podemos considerar local o particular (Grupo , 1993: 234) relativa a una marca concreta, para la que el rojo, es vitalidad, felicidad, alegría y, para la que las curvas, son dinamismo, juventud, atractivo, expresiones visuales que adquieren diferente significado en otras Semióticas Visuales Corporativas, también de carácter local.

Existe, por supuesto, una base muy general que permite considerar la existencia de una Semiótica Visual Corporativa, aunque sea por el mero hecho de saber identificar un logo-símbolo como tal y no como una fotografía, una señal de tráfico, o una obra pictórica. Sin embargo, es un código muy vago y ambiguo, dado que un mismo color, una misma forma, una misma textura, en definitiva, una expresión, aparentemente igual, puede encerrar un contenido muy distinto. En esta Semiótica Visual Corporativa, los elementos que constituyen el plano de la expresión son todos 
aquellos estímulos visuales que percibimos y que configuran el logo-símbolo, en cuanto a signo visual; el plano del contenido está configurado por el conglomerado semántico que corresponde a cada uno de esos estímulos, esto es, el significado que tienen y que aparece plenamente ligado a los valores corporativos que identifican a la marca a la que representan. Sin embargo, como ocurre con casi todos los códigos visuales, las relaciones semióticas que se establecen entre el plano de la expresión y el plano del contenido son inestables, al responder a reglas y principios poco cambiantes desde el punto de vista de una correspondencia biunívoca.

La conformación de la Semiótica Visual Corporativa General como un código semiótico débil, reside en esta inestabilidad, que complica la definición de un grado cero. La complejidad conceptual que encierra el grado cero ha generado múltiples debates, algunos de los cuales lo hacen sinónimo de desvío o alteración, marca, redundancia, autocorrección e invariante, determinando varias dimensiones o perspectivas de una misma concepción. El Grupo. Mi (1987) se refiere, en primer lugar, a la definición intuitiva del grado cero, manifestando que "se puede definir como un límite hacia el cual tiende, voluntariamente, el lenguaje científico" (Grupo Mi, 1987: 77), pero la constante reformulación de este lenguaje, según cada caso concreto que se estudie, desbarata la exigida univocidad que ha de manifestar el grado cero; esto lleva al Grupo Mi, (1987) a considerar dos posibles dimensiones del grado cero:

- El grado cero absoluto, sería el discurso llevado a sus semas esenciales, esto es, a los semas que resultan imprescindibles para su significación (Grupo , , 1987: 78). 
- El grado cero práctico, sería el discurso que contiene todos los semas esenciales, más un número de semas laterales reducidos al mínimo en función de las posibilidades del vocabulario (Grupo Mi, 1987: 78).

No obstante, el Grupo Mi, (1987: 79) advierte que tal definición es más una promesa que un instrumento eficaz que depende de los procedimientos utilizados para alcanzarlo; sin embargo, al asignarle un lugar fuera del lenguaje, apoyan la concepción de grado cero como límite (Grupo Mi, 1987: 79).

En ámbito del contenido, la mayor dificultad procede de lo que el Grupo Mi (1993: 44) denomina la problemática homologación del signo visual, refiriéndose a la ambigüedad polisémica que manifiestan las diferentes expresiones que utilizan los distintos logo-símbolos. Esto lleva a considerar que, si semióticamente hablando, a cada expresión le corresponde un contenido de todos los posibles, el resto serán desviaciones retóricas.

Esta complejidad también la ha apuntado Javier González Solas (2002: 142), al referirse a los diferentes significados que podemos encontrar en la Identidad Visual Corporativa de una empresa, determinando que el primer significado es el índice, aún presente y unido al mundo y, el segundo, la denotación, una definición del significado principal. Para este autor, el logo-símbolo puede entenderse como una señal que indica a una entidad corporativa, y cuyo mensaje sólo puede comprenderse por el contrato enunciativo, que exige el conocimiento previo del contexto de tales signos visuales correspondientes a un idiolecto concreto (González Solas, Javier, 2002: 142). Si se considera que todas las asociaciones entre expresión visual y contenido apropiado son convencionales, debe determinarse que el significado apropiado dependerá, sólo en pequeña medida, del grado de iconicidad de la expresión y, en gran medida, del contexto sociocultural en el que emerja el mensaje, así como de las intenciones de la empresa emisora con ese mensaje: 
"Entonces nos encontramos con la paradoja de que el significado denotado, es ya forzosamente, connotado, debe remitir a algo que no es la entidad en sí, por una parte al contexto sociohistórico, y por otra, a los atributos que ella se autoatribuye o que quiere manifestar" (González Solas, Javier, 2002: 143).

\subsection{El logo-símbolo, signo visual.}

El logo-símbolo es un signo de expresión esencialmente visual, y portador de un significado. Es importante, en este sentido, mencionar las aportaciones de Louis Hjelmslev (1987) porque pueden ser de gran utilidad en el análisis que se propone, pero teniendo en cuenta que él hablaba de Lingüística, mientras que aquí se hace referencia a un código logo-simbólico esencialmente visual.

Para Louis Hjelmslev (1987: 177), toda Semiótica, aún aquella cuyo significante sea de naturaleza no lingüística, está constituida por dos planos, que él denominó "lados del lenguaje", el de la expresión y el del contenido, y cada uno de los cuales, implica dos estratos, la forma y la sustancia:

- Expresión y contenido constituyen dos planos funtivos en un signo, porque contraen la función de signo; se trata de planos solidarios, dado que la expresión lo es, únicamente, en virtud de un contenido y viceversa. No cabe expresión sin contenido ni contenido sin expresión.

- La sustancia del contenido es el continuum amorfo de pensamiento, de ideas, de sentido, antes de que en cada código reciba una forma determinada; puede equipararse a todos los paradigmas ideológicos que se manifiestan en un código determinado. 
- La forma del contenido es la conformación específica que, en cada código, recibe la sustancia del contenido. Se trata de la imagen mental, el concepto. Lo que caracterizaría a un código visual concreto (como el constituido por los logos, o el de las señales de tráfico, o la publicidad visual, etc.), es la forma del contenido, puesto que la sustancia del contenido es la misma (todos son códigos visuales), independientemente de su forma (logotipos, señal de stop, anuncio de automóvil, etc.). Podría equipararse al significado, aunque no es del todo adecuado.

- La sustancia de la expresión es el continuum amorfo, en que cada código, incluye arbitrariamente cierto número de figuras; este continuum amorfo es previo a que cada código lo revista de una forma determinada. Se refiere a las potenciales relaciones que pueden actualizarse en un acto comunicativo.

- La forma de la expresión es la sustancia de la expresión ya estructurada en los significantes del código visual. Puede equipararse al significante, aunque no es del todo correcto.

Las sustancias están completamente ligadas a las características físicas, ideológicas y culturales del código utilizado; mientras que las formas ofrecen los modelos conceptuales dentro de un código concreto.

Roland Barthes (1987) resume que el plano de los significantes constituye el plano de la expresión y el plano de los significados el plano del contenido. Pero al referirse al significante, manifiesta: "Hemos de tomar la decisión de abusar, todavía por mucho tiempo de la palabrd" (Barthes, Roland, 1987: 96); de esta manera, refiriéndose a la profundidad y ligereza del significante, determina la dependencia que manifiesta cualquier código del sistema lingüístico. 


\section{.} ISSN: 1576-3420 DOI: http://dx.doi.org/10.15198/seeci.2008.17.17-56

Estos conceptos se pierden, en gran medida, en el planteamiento semiótico del Grupo Mi (1993), que sólo los tiene en consideración cuando analiza los elementos de los signos plásticos y de manera parcial. Mencionado grupo de investigadores (Grupo Mi, 1993: 167-228) considera que los llamados signos plásticos (los no figurativos), pueden analizarse según los parámetros que definen su forma, su textura y su color y mediante las relaciones que mantienen. Consideran, que en este caso, el significado, se manifiesta como relacional, al determinar que las unidades plásticas están más estructuradas por el sistema biplanar (expresión-contenido) que por el código visual.

En este caso, no se considera la existencia de tal diferenciación (plástica y figurativa), sino que se entiende que cada signo visual tiene un significante (plano de la expresión, forma de la expresión) que corresponde a un referente real e invoca un tipo (modelo, forma del contenido) y cuya interpretación, por parte del receptor, depende, entre otras cosas, de aspectos culturales y contextuales inevitables (sustancia del contenido), y de las potenciales relaciones que pueden actualizarse en un acto de comunicación visual corporativa concreto (sustancia de la expresión).

La Semiótica Visual Corporativa es de gran complejidad dada la dificultad de establecer un significado denotado a partir de una expresión puramente simbólica; los logos suelen presentar un grado de iconicidad muy bajo, es decir, no tienden a parecerse al referente real al que representan, por lo que su significado es connotado.

A diferencia de la Lingüística (código muy estable), la Semiótica Visual Corporativa es una Semiótica débilmente codificada. La formalización de sus dos planos, expresión y contenido, es vaga e inestable, de manera que una determinada expresión en un logo-símbolo puede tener una significación muy diferente a esa misma expresión en otro logo-símbolo. Sin embargo, el logo-símbolo de Coca-Cola, así como otros 
muchos de considerable trayectoria y fuerza social tienen, prácticamente, las mismas connotaciones en todo el mundo. Esto es lo que lleva al Grupo Mi a considerar que los logotipos más famosos pertenecen a una Semiótica fuertemente codificada, como las lenguas y los iconos (Grupo Mi, 1993: 236). En este aspecto, puede manifestarse otra modesta disonancia con este grupo investigador, pues puede entenderse que si un logo-símbolo logra significar lo mismo en todas los espacios y momentos, independientemente de las posibles interferencias contextuales a las que se enfrenta, es probablemente, por la existencia de una serie de estrategias retóricas que desarrollan para lograr que todos interpretemos el logo de Coca-Cola como "la chispa de la vidd" o "la sensación de vivir".

\subsubsection{Los elementos semióticos que componen el logo-símbolo.}

El logo-símbolo, en cuanto a signo visual, puede ser analizado según el modelo utilizado por el Grupo. (1993: 109-166) para el análisis de los signos visuales icónicos; este modelo de análisis se basa en las consideraciones teóricas de Charles Kay Ogden y Ivor Armstrong Richards (1923) quienes consideran que el signo puede definirse a partir de su estructura tripartita y relacional. Entendido así, el logosímbolo, está constituido por tres partes:

a) El referente: El referente de un signo visual, según el Grupo. (1993: 121-122), es un designatum actualizado, es decir, el objeto entendido como miembro de una clase validada por la existencia de un tipo con el que se corresponde; este referente es particular, único y tiene características físicas propias, que le convierten en real. En el caso de los logo-símbolos, el referente es la empresa o compañía a la que representa el signo visual, lo que ofrece a ese signo, desde su construcción misma, un estatus de símbolo: "Los elementos plásticos remiten a una significación, y ésta significación remite a un referente, que es la entidad, por lo que habitualmente se habla de simbolización" (González Solas, Javier, 2002: 142). 
b) El significante: El significante de un signo visual puede definirse como un conjunto de estímulos visuales que corresponden a un tipo estable que el receptor del mensaje es capaz de identificar a partir de los rasgos de ese significante, pudiéndolo asociar además, a un referente reconocido como hipóstasis ${ }^{2}$ del tipo (Grupo. , 1993: 122). El significante mantiene relaciones de transformación y cotipia $^{3}$ con el referente, dado que, aunque el significante procede del referente (de la realidad) manteniendo con él un grado de iconicidad (semejanza), siempre queda modificado por los estímulos visuales escogidos por el emisor del mensaje visual para su construcción.

c) El tipo: El tipo de un signo visual es un modelo interiorizado y estabilizado al alcance de los conocedores del código (Grupo. , 1993: 122); se trata de una representación mental que surge de un proceso de integración, cuya función es garantizar la exigida equivalencia entre el referente y el significante, facilitando al receptor, un significado acorde al pretendido por el emisor. El tipo posee características conceptuales, pero no físicas. Semiotizar consiste en la configuración de tipos, es decir, en crear modelos teóricos ignorando rasgos particulares para despejar los generales. En la base de todo tipo visual hay un umbral, lo que significa que nuestro aparato perceptivo ignorará todo estímulo inferior al umbral escogido, exagerando todo estímulo que supere ese umbral. Cuanto más se eleve el umbral, más abstractos serán los tipos obtenidos (Grupo ，1993: 85).

Todo tipo, puede ser percibido, bien, como parte de un conjunto, bien, como ese conjunto mismo, por ello, se podría hablar de supratipos (aquellos tipos, que

\footnotetext{
${ }^{2}$ Hipóstasis. Término griego equivalente a sustancia, en tanto, que realidad de Ontología (parte de la Filosofía, que se ocupa de lo que existe), que puede traducirse, como verdadera realidad.

3 El Grupo Mi define la relación de cotipia como un contrato que se establece entre un significante y un referente conmensurables (Grupo Mi, 1993: 130). Klinkenberg determina que dos elementos en cotipia deben considerarse equivalentes uno del otro y no dos muestrarios distintos de la misma categoría (Klinkenberg, 2003: 18).
} 
engloban otros tipos) y de subtipos (aquellos tipos, que constituyen un tipo de nivel superior). Pero, de cualquier forma, los estatutos de tipo, subtipo y supratipo, están en función del nivel de análisis determinado, por tres factores:

- La presencia de determinantes particulares: Algunas propiedades visuales pueden conducir a una decodificación u otra de un signo visual.

- El contexto visual: El resto de signos visuales que acompañen a un signo determinado pueden provocar que se decodifique de un modo concreto.

- El contexto pragmático: A consecuencia de la presencia del signo en un enunciado que pertenece a un código puede ser leído de una manera u otra.

Generalmente la ideología y la cultura de cada contexto establecen los niveles de análisis ideales; en nuestra civilización, el hombre es la medida de todas las cosas. En relación con esta forma de interpretar, el Grupo Mi (1993: 138) habla de los usos de los tipos, refiriéndose a las relaciones estabilizadas que un tipo mantiene con otros tipos; un ejemplo, son las relaciones funcionales que pueden darse entre un productor y su producto.

Entre estas tres dimensiones del signo, se establecen, tres relaciones dobles:

a) La relación que se establece entre el significante y el referente (Grupo Mi, 1993: 123-124): Entre significante y referente se establecen relaciones de transformación que pueden ser de dos tipos, dependiendo si el proceso es de emisión o de recepción del signo:

- En el proceso de emisión del signo, las transformaciones son aplicadas sobre un referente para elaborar un significante basado en la propia percepción de 
ese referente real. Se trata del proceso de construcción del significante a partir, de unas transformaciones del referente según unas reglas determinadas por un tipo estable, en las que el emisor debe basarse si pretende que el receptor interprete el signo en el sentido que pretende.

- En el proceso de recepción del signo, las transformaciones son aplicadas sobre el significante, de tal manera, que permitan postular a partir de ciertas características que posee ese significante, ciertas características del referente al que representa. En este caso, se trata de un proceso de reconstrucción del referente por transformación del significante, posible, gracias a los datos que nos proporciona el tipo conceptual.

El tipo o modelo conceptual se convierte en un elemento semiótico de gran potencia, no sólo por permitir la relación de cotipia entre referente y significante, estableciendo una serie de características regladas que ambos deben mantener, sino también posibilitando la equivalencia de dos significantes, al determinar una serie de transformaciones posibles y válidas para un modelo estable. Esto explica:

- Por un lado que una imagen guarde una relación de semejanza suficiente con su referente real para que el receptor pueda interpretarla en los términos pretendidos por el emisor.

- Por otro lado que una fotografía y un dibujo puedan tener un mismo referente y constituir un significante distinto (por la técnica-canal-expresión utilizados), pero estando referidos a un mismo tipo.

b) La relación que se establece entre el referente y el tipo (Grupo Mi, 1993: 124): Se producen dos posibilidades, según el proceso comunicativo en el que se dé la relación. 
- Al hablar de la relación referente-tipo, se hace referencia a una estabilización e integración de las propiedades de un referente en un modelo conceptual, es decir, los elementos juzgados como pertinentes son extraídos del referente (en el proceso de percepción del mismo) y añadidos al modelo que constituye el tipo conceptual. Esta relación se da en el proceso de recepción del signo.

- Si se trata de la relación tipo-referente, la relación se basa en una prueba de conformidad, que consiste en determinar las características modélicas de un tipo que recoge un referente para poder concluir si ese referente real es o no una hipóstasis de ese tipo conceptual.

c) La relación que se establece entre el tipo y el significante (Grupo Mi, 1993: 124): La relación entre el tipo y el significante o es una relación de conformidad, o es una relación de reconocimiento, todo dependerá del inicio de la relación:

- En la relación tipo-significante, los estímulos visuales que conforman el significante son sometidos a un prueba de conformidad, al confrontarlos con un tipo; tal prueba de conformidad determina si ese significante es o no, hipóstasis de ese tipo.

- En la relación significante-tipo, se habla de reconocimiento del tipo, es decir, de determinar, a partir de una serie de estímulos, el tipo al que corresponden. El reconocimiento de un tipo, a partir de un significante, es conjetural, pues se da en virtud del estatuto lógico de los conceptos, relaciones y procesos implicados en el funcionamiento del signo visual.

La emisión de un mensaje visual (también logo-simbólico), consiste en la construcción de un discurso, a partir de una serie de transformaciones que, ejecutadas sobre un referente real, deben proporcionar un producto (significante) 
conforme a un modelo expresado por un tipo correspondiente a ese referente, garantizando así una relación de cotipia entre significante y referente. La recepción de estos mensajes consiste en identificar el conjunto de estímulos visuales (significantes) como procedente de un referente real que se corresponde con un tipo.

Todas estas condiciones de transformación y de conformidad deben respetarse simultáneamente, y manifiestan una jerarquización: Toda transformación está subordinada a la conformidad a un tipo, es decir, debe preservar la cotipia, lo que permite, al significante ser identificable como hipóstasis del tipo, del cual, el referente es también, una hipóstasis.

\section{Análisis semiótico del logo de Mozilla.}

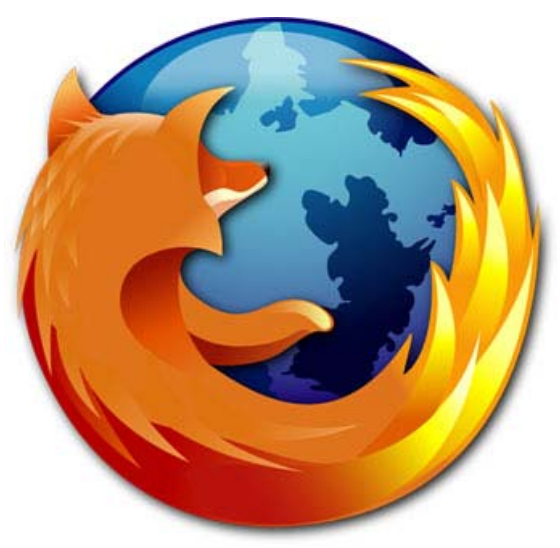


5.1. Modelo de análisis de las unidades de registro semiótico.
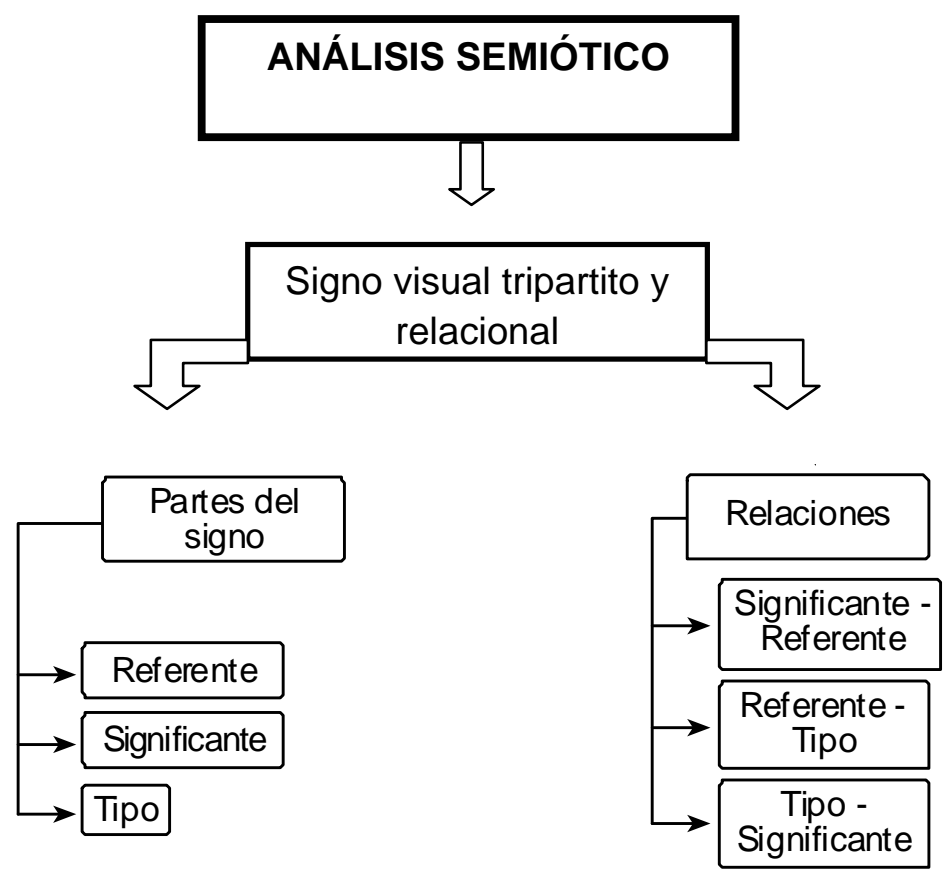

El análisis semiótico se ha desarrollado según una de las perspectivas de análisis utilizadas por el Grupo . (1993) en el desarrollo de sus teorías. Este análisis se fundamente en el modelo triangular de construcción del signo de Ogden-Richards (1923), que considera al mismo como una entidad tripartita y relacional.

El logo-símbolo, así entendido, está constituido por un referente, un significante y un tipo, entre los cuales se desarrollan relaciones que permiten, tanto su configuración misma, como su correcta interpretación. Las unidades de registro a analizar son:

\section{- Partes semióticas del logo-símbolo:}

a) Referente: La empresa real y física a la que representa el logo.

b) Significante: El conjunto de estímulos visuales que configura el logo. 
c) Tipo: El concepto al que apela mencionado logo-símbolo.

\section{- Relaciones entre las partes semióticas del logo-símbolo:}

a) Relación significante-referente-significante: Relación de transformación doble, en la que se sustenta, por un lado, la construcción del significante a partir del referente $y$, por otro, el reconocimiento del referente a partir del significante.

b) Relación referente-tipo-referente: Relación que permite, previo proceso de interiorización e integración de las aportaciones que un espectador recibe sobre un determinado referente, generar un tipo conceptual de ese referente, en este caso, las empresas con fines lucrativos.

c) Relación tipo-significante-tipo: Relación que permiten acceder al sentido del logo-símbolo según dos posibilidades:

o En la relación tipo-significante, a partir del tipo conceptual de la empresa correspondiente, mediante una prueba de conformidad a la que es sometido el significante del logo-símbolo, se determina el significado del mismo.

o En la relación significante-tipo, se produce el reconocimiento del tipo de una determinada marca o empresa, partiendo de los estímulos que recibimos y que componen el significante del logo-símbolo.

\subsection{Registro semiótico e interpretación de los datos.}

Mozilla Firefox se dio a conocer a partir de este símbolo visual, sin recurrir a una tipografía que identificase el producto-servicio al que se refería tal signo visual 
corporativo y designando más que una empresa en sí, un navegador, es decir, un producto concreto que permitía un determinado servicio.

Este logo-símbolo se ha convertido en uno de los símbolos corporativos más valorados y estimados por el espectador, algo que no sorprende si se tiene en cuenta la riqueza visual del mismo, con un cromatismo muy cuidado y un signo visual detallado que, a pesar de la complejidad visual que determina su esmerado detalle, no resulta un discurso visual barroco.

El detalle ofrece al signo visual un alto grado de iconicidad con ciertos objetos de la realidad natural, lo que incrementa la posibilidad de recuerdo, asimilación e integración del signo por parte del público; tales elementos son:

1. El globo terráqueo que representa el planeta Tierra o el mundo.

2. Un zorro que realmente pretende ser el icono de un animal en vías de extinción: el panda rojo o Ailurus fulgens, al que a veces se le llama en inglés fire fox, lo que significa, literalmente, "zorro de fuego".

Con mencionado símbolo, la Fundación Mozilla ha logrado identificar un producto de alta calidad y competitividad, convirtiendo el signo visual del zorro y el mundo en una sinécdoque metonímica que representa un conjunto de valores corporativos que no sólo identifican un producto concreto sino una filosofía comercial.

De este modo, y de forma muy similar a como lo han hecho otras muchas marcas con sus logo-símbolos, Mozilla Firefox ha conseguido una representación en la cultura visual internacional, logrando representar un tipo conceptual mediante diversas estrategias retóricas que permiten la construcción de un símbolo de gran fuerza visual. 


\subsubsection{El análisis del logo-símbolo de Mozilla Firefox como signo} visual de estructura tripartita y relacional.

Se propone en este trabajo el análisis semiótico del signo visual corporativo del navegador Mozilla Firefox según el modelo propuesto con inmediata anterioridad.

\section{- Partes semióticas del logo-símbolo:}

\section{a) Referente:}

El referente real al que representa este símbolo visual es muy diferente a los aparentes objetos de la realidad que quedan reflejados icónicamente en su expresión.

Realmente el símbolo formado por el globo terráqueo al que acaricia y posee un atractivo panda rojo que sobre él se superpone, representa más que una empresa, su producto estrella: el segundo navegador de Internet más extendido a nivel mundial. Se trata pues de la representación visual de un producto que permite un servicio, pero cuya marca ha sido capaz de generar una filosofía alternativa en el seno de la competencia, la comercialización y el mercado libre.

El símbolo manifiesta una Historia Corporativa, un Proyecto empresarial y una Cultura Corporativa recurriendo a un código visual que manifiesta un alto grado de semejanza o parecido con determinados objetos existentes en la realidad natural con mucha antelación a la fundación de la marca.

Esta apuesta por escoger como modelos visuales elementos reales tiene como contrapartida que el público no sepa interpretarlo en el sentido en que la marca Mozilla pretende, pero el éxito permite a la marca presumir de su acierto, algo que 
probablemente, no haya sido gratuito, sino que seguramente resida en la utilización de las estrategias comunicativas más acertadas.

\section{b) Significante.}

El significante del símbolo corporativo está formado por dos subformas una de mayor importancia por su posición y denominación respecto a la otra, pero que sin embargo, es incapaz de lograr, de forma aislada, el significado completo que encierra el símbolo corporativo.

El panda rojo o zorro de fuego es la subfoma preferente; por sí sólo es un elemento que tiene su correspondencia con un estereotipo de nuestro repertorio (el de un zorro de fuego), algo que no diferencia a esta subforma de la otra que configura el símbolo corporativo, pues el globo terráqueo también tiene su correspondencia en nuestro repertorio de tipos.

Ambas subformas poseen, por tanto, la fuerza visual suficiente y el grado de iconicidad necesario para que las podamos identificar de forma autónoma con un tipo conceptual, pero tal identificación desarrollada de forma aislada no será suficiente para lograr el significado pleno que alcanza el conjunto simbólico.
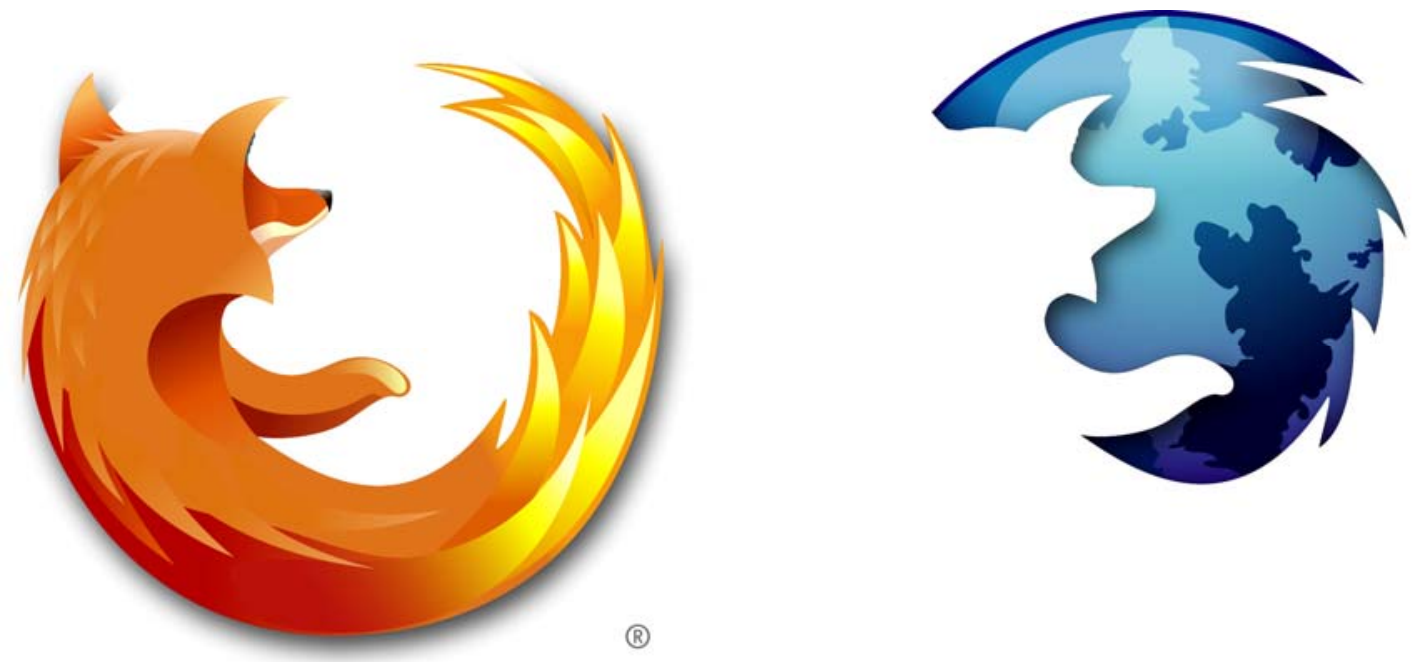
Llorente Barroso, María del Carmen (2008): Análisis semiótico del logo de Mozilla. No 17. Noviembre. Año XII. Páginas: 17-56

ISSN: 1576-3420 DOI: http://dx.doi.org/10.15198/seeci.2008.17.17-56

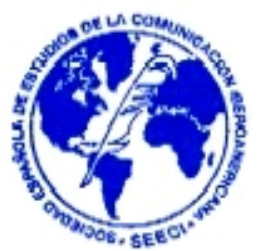

Por ello, podemos determinar que son las dos formas en su conjunto las que logran una Gestalt que supera el significado de la suma de sus elementos, logrando una identificación más definitiva con el tipo "Mozilla Firefox" y consiguiendo, sólo con el tiempo y con un trabajo de comunicación simultáneo, que el público la identifique con esencia identitaria del navegador.
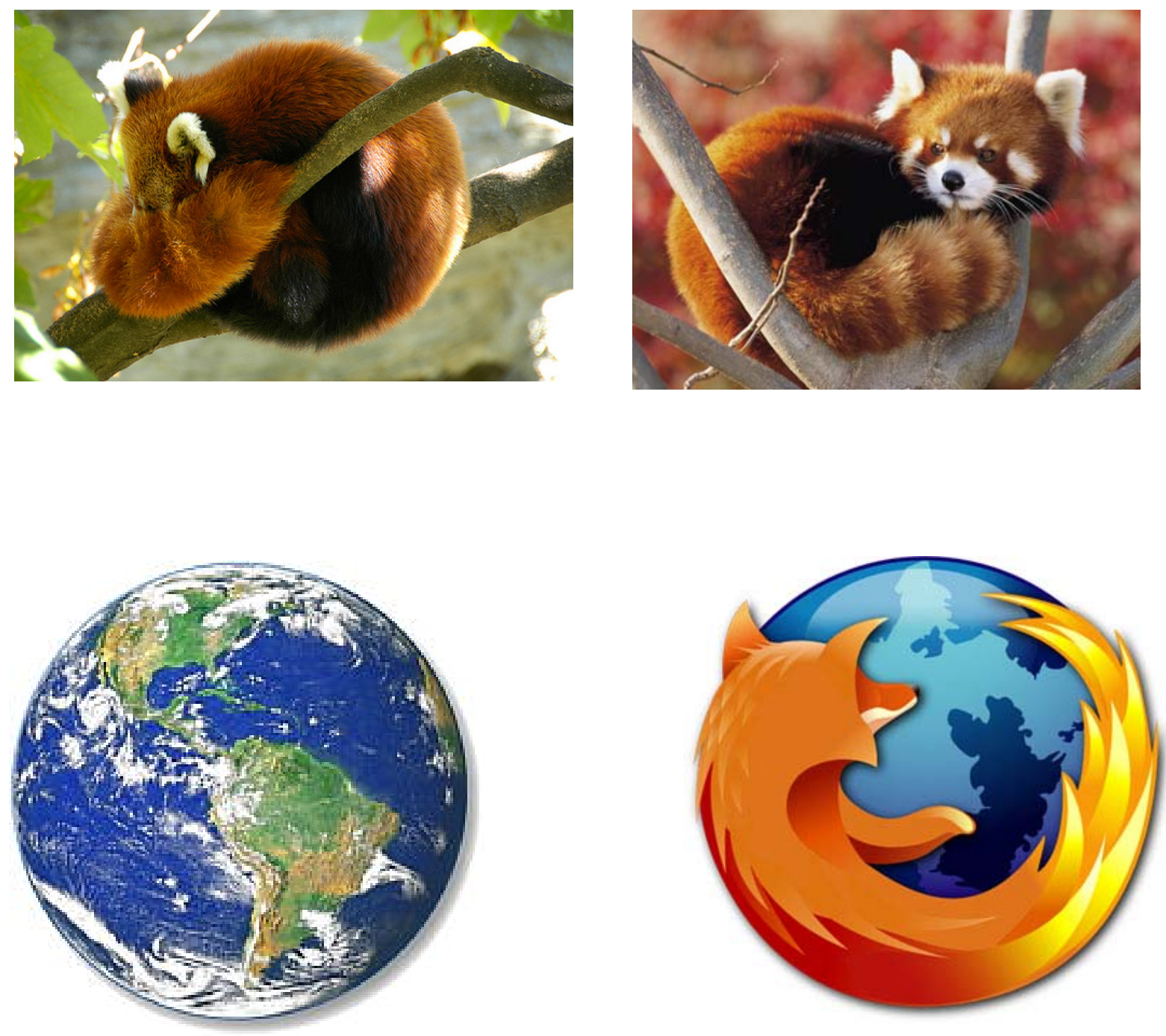

Pese a tratarse de una forma en la que podemos detectar una relación de cotipia muy significativa entre las dos formas visuales que componen el significante y dos referentes del mundo natural real (el panda rojo y el planeta Tierra), debe tenerse 
presente que realmente es un signo visual corporativo en el que el significante no guarda relación alguna con el referente al que realmente representa: un navegador.

Por tanto, la relación de cotipia entre el símbolo y el referente al que representa es mínima, existiendo un alto grado de abstracción, no ya porque el logo-símbolo prescinda de la concreción de la palabra para expresar la denominación de la marca a la que representa (de hecho, el nombre de la marca manifiesta la misma ambigüedad que uno de los elementos del símbolo), sino porque ese signo visual que, en principio puede inducir a un significado relacionado con un tipo, encierra en realidad otro mucho más complicado: la esencia identitaria de un navegador de Internet.

\section{c) Tipo.}

El tipo, en este caso, no sería una suma de los significados que culturalmente se han asentado sobre los dos unidades que configuran el significante (el panda rojo y el globo terráqueo), sino que la marca del navegador ha conseguido crear un paradigma conceptual propio que define su esencia identitaria y aflora en la mente de los públicos cuando ven su símbolo visual corporativo.

El tipo de Mozilla Firefox es el concepto que el público ha logrado asentar sobre el navegador de Internet, gracias a todas las informaciones que recibe sobre él, ya tengan o no voluntad comunicativa por parte de la marca.

Mozilla Firefox, es una de las pocas marcas que han conseguido expresar visualmente su identidad sin recurrir a un código lingüístico, todo un reto en un mundo en el que es difícil seducir con belleza visual. Para ello utilizará una estrategia más próxima a la de Apple que a la de Nike, dado que utiliza signos visuales reconocibles en objetos reales y a los que dota de una nueva dimensión semántica. 
La ventaja que tiene apostar por un signo que responde a un tipo preexistente, es que el público dispondrá de una serie de elementos nemotécnicos que le permitirán memorizar y recordar con más rapidez las características visuales del signo gráfico. El inconveniente reside en el riesgo de que el público no identifique el signo con el tipo conceptual que pretende la marca.

Para alcanza el éxito, Mozilla Firefox no ha precisado mucho tiempo; su símbolo, creado en 2004, lleva siendo reconocido a escala internacional casi desde que surgió. $\mathrm{Ni}$ siquiera ha necesitado el frecuente recurso al elemento tipográfico, algo muy frecuente entre todas las marcas (incluidas las que terminan apostando por una representación puramente simbólica), como estrategia para que el público asocie en nombre al símbolo.

Desde una perspectiva formal, únicamente referida al signo visual que representa a la marca y no a los referentes reales a los que expresa con alto grado de iconicidad, el símbolo de Mozilla Firefox, es un tipo perteneciente al supratipo "logo-símbolos", categoría que concentra una serie de subtipos que comparten o no los tipos de ese supratipo. En este caso sólo comparte con el resto de los logos, el subtipo de "símbolos corporativos" y el de los "colores corporativos" (los de Mozilla Firefox, estrictamente hablando serían naranjas y azules).

\section{- RELACIONES ENTRE LAS PARTES SEMIÓTICAS DEL LOGO-SÍMBOLO:}

\section{a) Relación significante-referente-significante.}

La transformación entre el referente y el significante que se da en el caso de Mozilla Firefox es de un alto grado de abstracción si se tiene en cuenta que es un símbolo que representa un navegador $y$, consecuentemente, no mantiene ningún tipo de relación icónica con el referente real al que expresa, aunque mantenga un alto grado de iconicidad con otros objetos de la realidad natural. Por ello, esta relación es una 
relación simbólica, basada en un conjunto de convencionalismos aprovechados por la marca.

La relación de cotipia se mantiene en un nivel de sentido diferente al que realmente la marca sugiere visualmente, lo que podría provocar que el espectador no identificase el signo visual tal y como Mozilla Firefox pretende. Esto exige a la marca desarrollar un importante esfuerzo comunicativo con el fin de que el público interprete el símbolo en la orientación marcada por la marca emisora del mensaje visual.

\section{b) La relación referente-tipo-referente.}

La relación referente-tipo es la que nos permite configurar el modelo conceptual de la marca Mozilla Firefox. Para ello, como espectadores, desarrollamos un proceso de integración de todas las informaciones que recibimos de la marca, tengan o no voluntad comunicativa por parte de la misma. De este modo se genera en nuestra mente el concepto de la marca del navegador como el de una firma competitiva por su excelente calidad y, especialmente, por tratarse de un software gratuito.

La construcción de este tipo es imprescindible para que el público pueda interpretar el signo visual en el sentido que la marca pretende, lo que exige a la marca invertir cuantiosas sumas en Comunicación Corporativa.

Por la trascendencia internacional de la marca, cada vez mayor, puede determinarse que Mozilla Firefox ha logrado con éxito expresar su Identidad Corporativa en un símbolo visual atractivo y de gran potencia simbólica que los espectadores son capaces de interpretar correctamente, pese a utilizar un referente equívoco. 


\section{c) Relación tipo-significante-tipo.}

Esta relación doble es la que permite, en el sentido tipo-significante, determinar si el conjunto de estímulos visuales que componen el significante son una hipóstasis del tipo "Mozilla Firefox" al someterlos a una prueba de conformidad, mediante la cual, se comprueba su correspondencia a los rasgos de tal paradigma conceptual. La prueba de conformidad también permite, a los receptores del mensaje, diferenciar significantes visualmente similares pero conceptualmente diferentes. De esta manera, el espectador diferencia el símbolo del navegador de una fotografía de un panda rojo o de un globo terráqueo utilizado en Geografía.

En la relación significante-tipo se desarrolla el procedimiento inverso, esto es, el reconocimiento del tipo de "Mozilla Firefox" a partir del significante del signo visual; partimos entonces del significante, es decir, de un conjunto de estímulos visuales que percibimos y debemos de ir asociando a un tipo de nuestro repertorio: Comprobamos si un conjunto de características visuales se combinan adecuadamente para configurar una forma asociable al tipo de "Mozilla Firefox".

\section{Conclusiones.}

Los aprendizajes más interesantes que se pueden extraer en el caso particular que se ha analizado, pueden sintetizarse en los siguientes puntos:

1. El símbolo corporativo de Mozilla Firefox manifiesta una estructura tripartita y relacional:

- La estructura en cuanto a signo tripartito le convierte en un significante de expresión exclusivamente visual que representa a un referente real (un 
navegador de Internet), evocando un tipo conceptual en las mentes de sus receptores. Mozilla Firefox ha logrado expresarse visualmente a partir de un único signo de gran capacidad simbólica; sin embargo, este logro, que muy pocas empresas consiguen, no es ni fácil ni inmediato. El público necesita tiempo para asociar a ese conjunto visual un tipo conceptual que se ha traducido en una Imagen Corporativa cuidada.

- Entre estos elementos se establecen relaciones esenciales para lograr la configuración del signo visual corporativo:

o La relación entre significante-referente-significante permite la asociación entre el significante y el referente del logo-símbolo que, en este caso, se fundamenta en una relación de cotipia del símbolo respecto a un referente real que no representa (Tierra y panda rojo) y al que recurre para cargarse de connotaciones simbólicas, determinando un alto grado de abstracción.

o La relación entre referente-tipo-referente logra configurar el tipo conceptual que permitirá a su público asociar el significante a un significado, mediante su vinculación a una realidad (referente).

o La relación entre tipo-significante-tipo permite, partiendo del tipo conceptual, llegar al significado del significante sometiéndole a una prueba de conformidad o, partiendo del significante, llegar al significado mediante el reconocimiento del tipo.

2. Así, Mozilla Firefox, consigue la construcción de un código visual propio de la marca, con un significado asociado a su Imagen Corporativa y diferente al sentido denotado de los elementos constitutivos de su signo visual corporativo, lo que le convierte en simbólico y connotado. Este código puede entenderse como una Semiótica Visual Corporativa de carácter local, porque tales elementos constitutivos pueden adquirir significados diferentes en otros logo-símbolos. 
Extrapolando estas conclusiones a un ámbito general se pueden deducir las siguientes conclusiones de interés:

1. Existe una Semiótica Visual Corporativa muy general a la que se ciñen las Semióticas Visuales Corporativas locales que desarrolla cada empresa y cuyas significaciones se construyen débilmente por su alto grado connotado. Los logosímbolos, popularmente conocidos como logotipos, configuran un código autónomo de potente carga simbólica, que permite hablar de una Semiótica Visual Corporativa. Javier González Solas (2002) prefería hablar de un dialecto de un código más amplio para referirse al lenguaje logo-simbólico. Compartiendo una posición más atrevida con el Grupo Mi (1993), se puede determinar que los logos constituyen un código autónomo, pero para que ese código pueda designarse como una Semiótica fuertemente codificada, es preciso tiempo y un importante esfuerzo comunicativo por parte de la marca. En este sentido, la Semiótica Visual Corporativa se configura como poco codificada, inestable y polisémica, pues sus significados dependen del uso que pretenda la marca. No obstante, pese a la localidad manifiesta de los códigos visuales de las diferentes marcas, existe una serie de índices generales, que posibilita la existencia de esa Semiótica Visual Corporativa, la cual, permite identificar un logosímbolo como tal y no como otro tipo de signo visual.

2. Esa Semiótica hace corresponder un plano de la expresión a un plano del contenido; el plano de la expresión, está conformado por los estímulos visuales que constituyen el logo-símbolo, mientras que el plano del contenido, está configurado por los significados que se atribuyen a esos estímulos y que, en el caso de los logosímbolos son especialmente simbólicos. La base simbólica de todo logo manifiesta la complejidad semiótica del código al que responde y, consecuentemente, la dificultad para establecer un grado cero.

3. A la complejidad de la disciplina de los signos, se suma, la propia naturaleza del mismo; una complejidad, que se ha tratado de subsanar, recurriendo a un análisis del signo visual corporativo desde la perspectiva de sustentada en la 
construcción triangular del signo planteada por Ogden y Richards (1923) y utilizada por el Grupo Mi (1993).

4. La aplicación de mencionado modelo para el análisis semiótico del signo visual corporativo, permite la extracción de un conjunto de conclusiones de interés, según las frecuencias, tendencias e intensidades observadas:

- Un logo manifiesta una estructura tripartita en la que se diferencian tres dimensiones interrelacionadas entre sí:

o Referente: La empresa real a la que representa el logo.

o Significante: El conjunto de estímulos visuales que configura la parte expresiva del signo visual corporativo.

o Tipo: La Imagen Corporativa de la empresa a la que representa el logosímbolo, entendida como concepto.

- Entre estas tres dimensiones de signo visual corporativo se establecen tres posibles relaciones que permiten la codificación constructiva del signo corporativo y su correcta descodificación e interpretación:

o Relación significante-referente-significante: Estas dos relaciones son de transformación, aunque esta transformación varía, en función del proceso de emisión o recepción. En el proceso de emisión, la transformación se ejerce sobre el referente para generar un significante; en el proceso de recepción, la transformación se lleva a cabo sobre el significante para poder, a través de él, acceder al referente real. Estas trasformaciones se basan en una relación de cotipia que manifiesta las similitudes expresivas necesarias para poder identificar al referente a partir del significante del signo referido a éste, pero que, en el caso de los logos, queda reducida a la mínima expresión, pues la relación significante-referente es simbólica. 
o Relación referente-tipo-referente: Esta relación permite, previo proceso de interiorización e integración de las aportaciones que, un espectador, recibe sobre una determina empresa (ya tengan o no voluntad comunicativa por parte de tal compañía), generar, en la mente de cada espectador, el tipo conceptual o paradigma de esa empresa, cuya construcción final, dependerá de múltiples factores, pero siempre, aparecerá asociada al signo visual que representa a esa empresa, del que surge, por evocación simbólica, el referente real al que remite (la empresa) y el tipo conceptual al que se refiere (la Imagen Corporativa de esa empresa).

o Relación tipo-significante-tipo: Estas relaciones posibilitan el acceso al sentido del logo-símbolo según dos posibilidades: En la relación tiposignificante, a partir del tipo conceptual de la empresa mediante una prueba de conformidad que permite determinar si los estímulos que componen el significante son una hipóstasis de un tipo corporativo. En la relación significante-tipo, mediante el reconocimiento del tipo de una determinada marca a partir de los estímulos que componen el significante.

5. El significante de un logo tiende a manifestarse como transformación absoluta del referente al que representa (empresa o corporación), lo que determina que la relación de cotipia entre el referente real y el significante, sea mínima, lo que implicados importantes esfuerzos:

- Por un lado, el esfuerzo que ha desarrollar el receptor para poder acceder al mensaje que encierra un significante de tal grado de abstracción respecto a su relación con su referente real.

- Por otro lado, el esfuerzo comunicativo que debe emprender una compañía para orientar al receptor de su logo-símbolo en la correcta interpretación del 
mismo. La correcta descodificación de un logo exige la construcción previa de un tipo conceptual en la mente del público, que garantice la equivalencia entre el referente (la empresa) y el significante (signo visual corporativo). No obstante, la construcción de este tipo conceptual es lenta y compleja, tendiendo a precisar una importante inversión comunicativa por parte de las empresas que facilite al público la introyección de ese concepto sobre lo que las empresas son, así como, un esfuerzo, por parte del público para el desarrollo de ese proceso de integración y asociación.

\section{Bibliografía}

BARTHES, Roland (1987, original de 1984): El susurro del lenguaje: Más allá de la palabra y la escritura, Colección Paidós Comunicación, Número 28, Ed. Paidós Ibérica. Barcelona.

CHAVES, Norberto (1988): La Imagen Corporativa: Teoría y metodología de la identificación institucional. Colección GG Diseño. Ed. Gustavo Gili. Barcelona.

ECO, Umberto (2000, original de 1976): Tratado de Semiótica General, Colección Biblioteca Umberto Eco. Palabra en el tiempo. Número 122. Ed. Lumen. Barcelona.

GONZÁLEZ SOLAS, Javier (2002): Identidad Visual Corporativa: La imagen de nuestro tiempo. Ed. Síntesis. Madrid.

GREIMAS, Algirdas J. (1994, original de 1978): "Semiótica Figurativa y Semiótica Plástica", en GREIMAS, Algirdas J.; FLOCH, Jean Marie; THÜRLEMANN, Félix; BLANCO, Desiderio; BORDRON, Jean-Frnaçois; STOCKINGER, Peter; FONTANILLE, Jacques; SAUDAN, Alain (1994): Figuras y Estrategias: En torno a una Semiótica de 


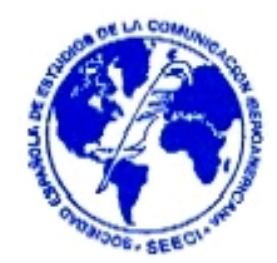

lo Visual. Colección Lingüística y Teoría Literaria. Ed. Siglo XXI Editores y Benemérita Universidad Autónoma de Puebla. Méjico DF.

GREIMAS, Algirdas J. y COURTÉS, Joseph (1982 original de 1979): Semiótica: Diccionario razonado de la teoría del lenguaje. Colección Biblioteca Románica Hispánica. Diccionarios. Número 10. Ed. Gredos, Madrid. Hernández Aguilar, Gabriel (1994)

GREIMAS, Algirdas J.; FLOCH, Jean Marie; THÜRLEMANN, Félix; BLANCO, Desiderio; BORDRON, Jean-Frnaçois; STOCKINGER, Peter; FONTANILLE, Jacques; SAUDAN, Alain (1994): Figuras y Estrategias: En torno a una Semiótica de lo Visual, Colección Lingüística y Teoría Literaria. Ed. Siglo XXI Editores y Benemérita Universidad Autónoma de Puebla. Méjico DF.

GRUPO Mi, (1993, original de 1992): Tratado del signo visual: Para una Retórica de la Imagen. Colección Signo e Imagen. Ed. Cátedra. Madrid.

GRUPO Mi, (1987, original de1982): Retórica General. Colección Paidós Comunicación. Número 27. Ed. Paidós Ibérica. Barcelona.

HJELMSLEV, Louis (1987, original de 1973): Ensayos Lingüísticos, Tomo II. Colección Biblioteca Románica Hispánica. Estudios y Ensayos. Número 177. Ed. Gredos. Madrid. HJELMSLEV, Louis (1987, original de 1947): "La estructura básica del Lenguaje", en HJELMSLEV, Louis (1987, original de 1973): Ensayos Lingüísticos, Tomo II. Colección Biblioteca Románica Hispánica. Estudios y Ensayos. Número 177. Ed. Gredos. Madrid. KLINKERBERG, Jean-Marie (2003): "Claves cognitivas para una solución al problema del iconismo", Iconismo. El sentido de las imágenes. Ed. Designis. Número 4. Págs:15 - 26. Buenos Aires. 
OGDEN, Charles Kay y RICHARDS, Ivor Armstrong, (1923), The meaning of meaning: A study of the influence of language upon thought and of the science of symbolism. Routledge \& Kegan Paul. Londres.

PEIRCE, Charles Sanders (1974, original de 1897): La ciencia de la Semiótica. Colección de Semiología y Epistemología. Ed. Nueva Visión SAIC. Buenos Aires.

SAUSSURE, Ferdinand de (1945, original de 1916): Curso de Lingüística General. Colección Filosofía y Teoría del Lenguaje. Ed. Losada. Buenos Aires.

VILLAFAÑE, Justo (1999): La gestión profesional de la Imagen Corporativa. Ed. Pirámide. Madrid. 